\title{
Sensitivity of the Baltic Sea salinity to the freshwater supply
}

\author{
H. E. Markus Meier ${ }^{1, *}$, Frank Kauker ${ }^{2}$ \\ ${ }^{1}$ Rossby Centre, SMHI, 60176 Norrköping, Sweden \\ ${ }^{2}$ Alfred Wegener Institute for Polar and Marine Research, Bussestr. 24, 27570 Bremerhaven, Germany
}

\begin{abstract}
The sensitivity of the Baltic Sea salinity to the freshwater supply is investigated using a 3-dimensional (3D) coupled sea-ice-ocean model. Today's climate is characterized by an average salinity of about $7.4 \%$ and a freshwater supply, including river runoff and net precipitation, of about $16000 \mathrm{~m}^{3} \mathrm{~s}^{-1}$. As recent results of some regional climate models have suggested a significant increase in precipitation in the Baltic catchment area due to anthropogenic climate change, in this study the response of salinity in the Baltic Sea to changing freshwater inflow is investigated. Of special interest is the possibility of the Baltic Sea becoming a freshwater sea with $0 \%$ salinity in the future. Therefore, model simulations with modified river runoff and precipitation for 1902-1998 were performed. The model is forced with daily sea-level observations in the Kattegat, monthly basin-wide discharge data, and reconstructed atmospheric surface data. The reconstruction utilizes a statistical model to calculate daily sea-level pressure, and monthly surface-air temperature, dew-point temperature, precipitation, and cloud-cover fields. It is assumed that the Kattegat deepwater salinity of about $33 \%$ will not change regardless of the changed freshwater supply. In most of the experiments the final stratification is almost in a steady state after $100 \mathrm{yr}$. We found that even for a freshwater supply increased by 100\% compared to 1902-1998 the Baltic Sea cannot be classified as a freshwater sea. A pronounced halocline still separates the upper and lower layers in the Baltic Proper, limiting the impact of direct wind mixing to the surface layer. A calculated phase diagram suggests that the relationship between freshwater supply and average salinity of the final steady state is non-linear. The results of the 3D model are in agreement with an analytical steady-state model assumed to work for freshwater changes smaller than $30 \%$. The latter model was applied in scenarios for the average salinity of the Baltic Sea.
\end{abstract}

KEY WORDS: Baltic Sea $\cdot$ Climate $\cdot$ Sea-ice-ocean modeling $\cdot$ Freshwater supply $\cdot$ Major Baltic inflows $\cdot$ Sensitivity of salinity $\cdot$ Scenarios $\cdot \Delta$-change approach

\section{INTRODUCTION}

The Baltic Sea is one of the world's largest brackishwater sea areas, with a large salinity gradient at the surface from almost oceanic conditions in the northern Kattegat to almost freshwater conditions in the northern Bothnian Bay. For 1902-1998 an average salinity of about $7.4 \%{ }^{1}$ has been calculated (Meier \& Kauker 2003). A large net freshwater supply mainly from river discharge of about 15000 to $16000 \mathrm{~m}^{3} \mathrm{~s}^{-1}$ in combination with the hampered water exchange through the Danish Straits causes this low salinity. Decadal salinity variations are of the order of $1 \%$, and no long-term trend is detectable during 1902-1998 (Meier \& Kauker 2003). About half of the decadal variability of average salinity is related to the accumulated freshwater inflow, whereas another significant part is related to variations of the low-frequency variability of the sealevel pressure (SLP) over Scandinavia (Meier \& Kauker 2003). The large inter-annual freshwater variability

\footnotetext{
${ }^{1}$ Since salinities were measured before the 1970 s in a variety of units without defined conversion to psu, we leave the salinity in this study dimensionless
} 


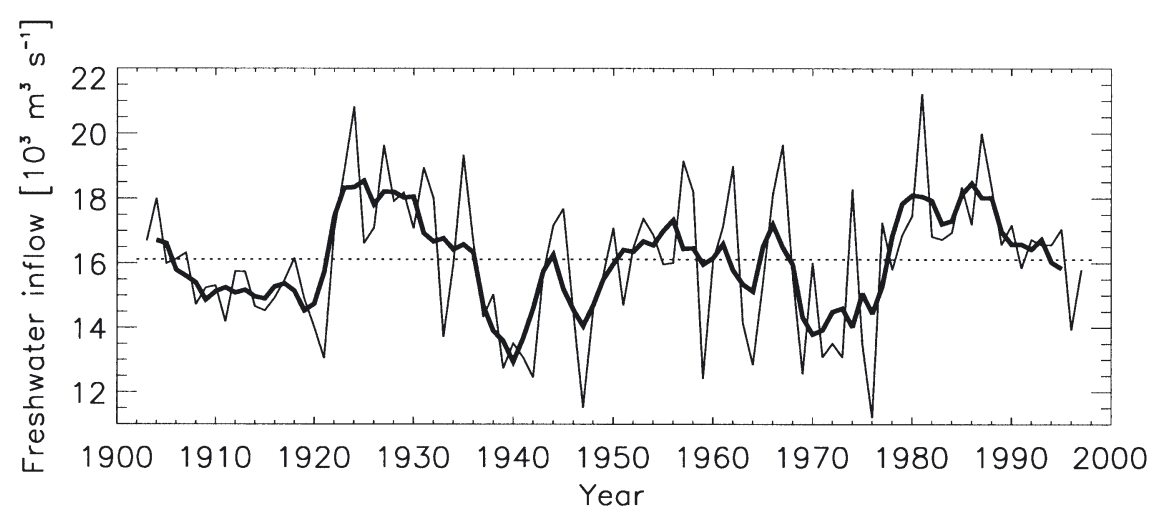

Fig. 1. Annual mean freshwater inflow, i.e. river runoff and precipitation minus evaporation (in $\mathrm{m}^{3} \mathrm{~s}^{-1}$ ), to the Baltic Sea without the Kattegat (thin line). In addition, the 4 yr running mean (thick line) and the total mean for 1902-1998 (dotted line) are shown

and systematic changes of the discharge seasonality due to river regulation have no significant impact on the long-term variability of salinity. Therefore, Winsor et al. (2001) called the system 'truly time-dependent' with a time scale much longer than the forcing time scale. The residence time of the freshwater in the Baltic Sea is about 35 yr (Meier \& Kauker 2003). It is calculated simply from the freshwater content divided by the freshwater inflow. This time scale is assumed to be the relevant response time scale for decadal variability of salinity in the Baltic Sea (Winsor et al. 2001).

Recent climate modeling results suggest that river runoff to the Baltic Sea may increase dramatically in the future, causing the Baltic Sea system possibly to drift into a new state (Omstedt et al. 2000, Meier 2002). Meier (2002) showed the impact of a $33 \%$ increase in runoff relative to the $18 \mathrm{yr}$ mean value of $15053 \mathrm{~m}^{3} \mathrm{~s}^{-1}$ for 1981-1998 on the Baltic Sea stratification. He found in a $10 \mathrm{yr}$ simulation that this additional amount of freshwater causes the Baltic Sea surface layer to drift to lower salinities (Meier 2002, his Fig. 3c). He also studied an extreme condition by integrating his model for 100 yr while assuming that no major saltwater inflow occurs. River runoff was increased by $16 \%$ relative to the mean value of $14085 \mathrm{~m}^{3} \mathrm{~s}^{-1}$ for $1902-1998$. In this sensitivity experiment, salinity in the Gotland Basin decreases in the surface layer by about 3 to $4 \%$ and in the bottom layer by about 6 to $6.5 \%$ (Meier 2002, his Fig. 4). The final quasi steady state is characterized by salinities of 2.8 (minimum at the surface) to $6.5 \%$ (maximum at the bottom). Upper and lower layers are still separated by a pronounced halocline. Based on these results, Meier (2002) concluded that it is very unlikely that the Baltic Sea will become a freshwater sea with $0 \%$ salinity in the future. Rodhe \& Winsor (2002) calculated a range of critical freshwater input for which the Baltic Sea would head towards a freshwater sea of 20000 to $28000 \mathrm{~m}^{3} \mathrm{~s}^{-1}$ using a semiempirical model. ${ }^{2}$ Obviously, the sensitivity of the sim- plified model presented by Rodhe \& Winsor (2002) is much higher than the sensitivity of the complex oceancirculation model presented by Meier (2002). However, in detail both studies are not comparable because Meier (2002) studied a worst-case scenario, assuming that no saltwater inflow occurs during the whole simulation period, whereas Rodhe \& Winsor (2002) calibrated their semi-empirical model using historical data of freshwater supply and salinity during 1921-1996. Thus, Rodhe \& Winsor (2002) assumed that the frequency of saltwater inflows does not change compared to the frequency in the last century.

Here, the impact of a changing freshwater forcing on the Baltic Sea stratification is studied systematically using a 3D coupled sea-ice-ocean model forced with the atmospheric variability of the last century. For 1902-1998 model simulations were performed with increased and decreased freshwater inflow. In contrast to the study by Meier (2002), the experiments are based upon the observed variability of the past $100 \mathrm{yr}$. The same reconstructed data as in Meier \& Kauker (2003) were used for atmospheric forcing.

The paper is organized as follows: In Section 2, the variability of the fresh- and saltwater inflows and of the average salinity during the last century are reviewed. We discuss the natural variability, because later in this study anthropogenic climate change will be compared to natural variability. The model strategy based upon a 3D Baltic Sea model is outlined in Section 3. The results of these sensitivity experiments are presented in Section 4. In Section 5, an analytical steady-state model for the Baltic Sea is used to analyze the results of

\footnotetext{
${ }^{2}$ The calculations of the Baltic Sea freshwater content and mean salinity presented by Winsor et al. (2001) and Rodhe \& Winsor (2002) were erroneous due to a fault in the hypsographic data used. This fault affects even the estimated sensitivity of salinity on the freshwater inflow calculated by Rodhe \& Winsor (2002). We refer here to recently corrected values (J. Rodhe pers. comm.)
} 
the more complex 3D model. Scenarios of the average salinity of the Baltic Sea are presented in Section 6 based upon the analytical steady-state model. The paper ends with a discussion and conclusions.

\section{FRESH- AND SALTWATER INFLOWS}

The stratification of the Baltic Sea is mainly determined by the high saline water entering the system from the North Sea and by the freshwater surplus including positive net precipitation, i.e. precipitation minus evaporation.

River runoff data of the Baltic catchment area have been analyzed by Mikulski (1986), Bergström \& Carlsson (1994) and Cyberski \& Wroblewski (2000). The total mean river runoff for 1902-1998 amounts to $14085 \mathrm{~m}^{3} \mathrm{~s}^{-1}$. There is no significant trend in the annual mean runoff. A total mean net precipitation of $2030 \mathrm{~m}^{3} \mathrm{~s}^{-1}$ for 1902-1998 has been calculated by Meier \& Kauker (2003) using a 3D coupled sea iceocean model. Consequently, the total mean net freshwater inflow for 1902-1998 amounts to $16115 \mathrm{~m}^{3} \mathrm{~s}^{-1}$ (Fig. 1). The lowest (11204 $\mathrm{m}^{3} \mathrm{~s}^{-1}$ in 1976) and highest (21 $221 \mathrm{~m}^{3} \mathrm{~s}^{-1}$ in 1981) annual values differ from the mean value by -30 and $+32 \%$, respectively. A lower long-term average net precipitation of $1152 \mathrm{~m}^{3} \mathrm{~s}^{-1}$ was found by Rutgersson et al. (2002) using a linear regression relationship between net precipitation, river runoff and maximum annual ice extent. However, the uncertainty is quite large. Rutgersson et al. (2002) estimated an error of the order of $1000 \mathrm{~m}^{3} \mathrm{~s}^{-1}$.

Most of the saltwater from the North Sea flows into the Baltic during large events, so-called major Baltic inflows (Matthäus \& Franck 1992). These events occur randomly during the winter season forced by a sequence of easterly winds lasting for $20-30 \mathrm{~d}$ followed by strong to very strong westerly winds of similar duration (Lass \& Matthäus 1996). In model simulations, Meier \& Kauker (2003) found about 180 saltwater inflows during 1902-1998 with a mean volume and a mean salt amount of high saline water with $S \geq 17 \%$ of $\bar{V}_{17}=105 \mathrm{~km}^{3}$ and $\bar{M}_{17}=2.3 \times 10^{12} \mathrm{~kg}$, respectively. The basic characteristics of simulated major Baltic inflows (Fig. 2) are relatively close to observations (Fischer \& Matthäus 1996). However, a quantitative validation is difficult as the number and intensity of observed inflows are very likely underestimated. Observations are sparse and not available for periods covering the world wars.

Comparing meteorological and oceanographic data during inflow seasons without and with major inflow events, Schinke \& Matthäus (1998) found statistically significant differences during the whole inflow season (September-March) only for river runoff. The statistically significance of the westerly wind speed differences is limited to isolated months. For 1951-1990, Lass \& Matthäus (1996) found an anomalous west wind component at the station Kap Arkona between August and October for seasons without major Baltic inflow compared to the seasons with major Baltic inflow. Lass \& Matthäus (1996) suggested that in years without major Baltic inflow the prevailing easterly winds during the preconditioning phase prior to the main inflow event are reduced. During this month-long preconditioning phase the Baltic Sea is emptied. Meier \& Kauker (2003) found in a model simulation 2 exceptionally long stagnation periods with significantly reduced salt transports into the Baltic Sea during the last century, the 1920s to 1930s and the 1980s to 1990s (Fig. 3). During these stagnation periods the average salinity of the Baltic Sea is about $0.5 \%$ lower compared to the mean value. The mean salinity for the last century calculated from observations amounts to $7.3 \%$ (Janssen et al. 1999). Meier \& Kauker (2003) found a mean salinity of $7.4 \%$. During

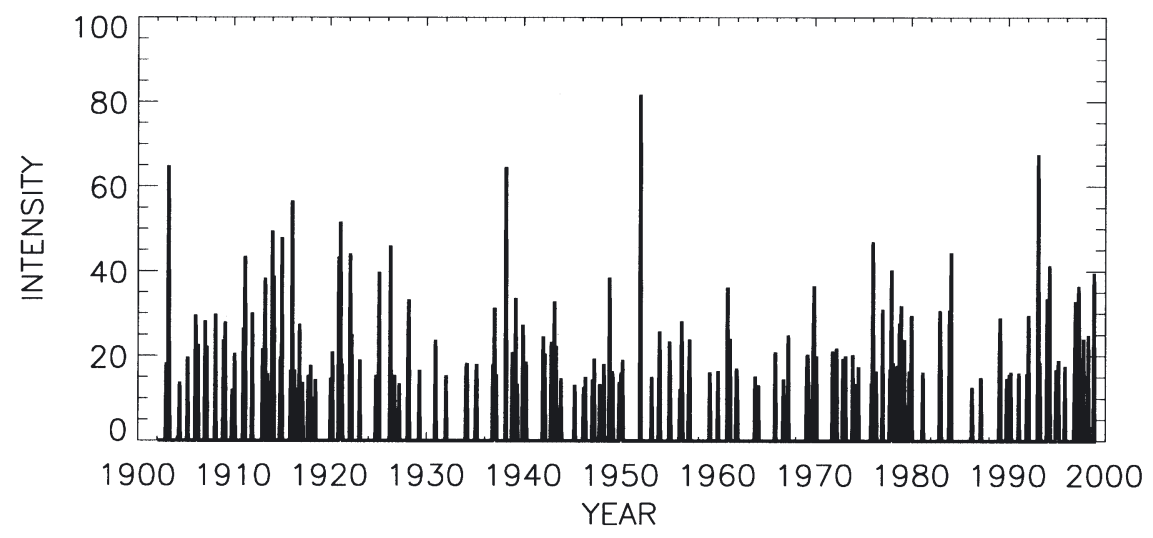

Fig. 2. Simulated major Baltic inflows during 1902-1998 as characterized by an intensity index based on the amount of salt (in kg) transported across the sills in water bodies with salinities $S \geq 17 \%$ divided by $10^{11} \mathrm{~kg}$ (according to Fischer \& Matthäus 1996) 


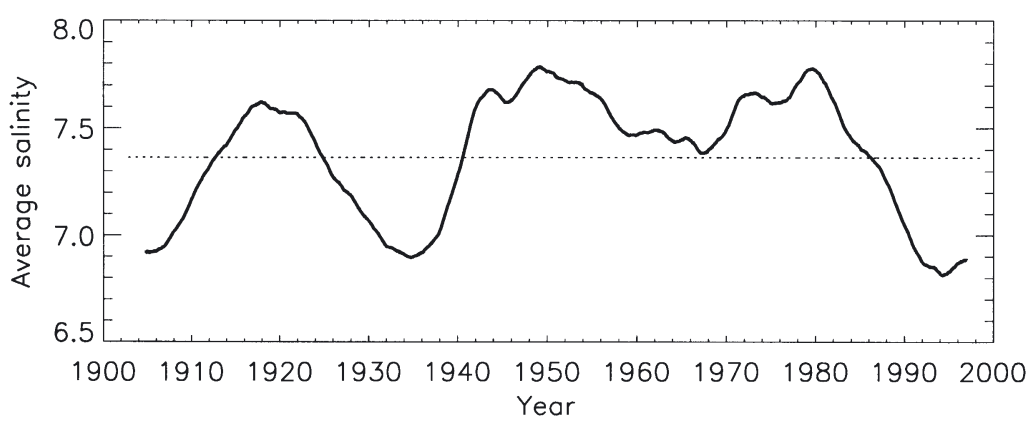

Fig. 3. Simulated 4 yr running mean average salinity (in \%o) of the Baltic Sea without the Kattegat (thick line). In addition, the total mean salinity for 1902-1998 is shown (dotted line). The model results are corrected following Meier \& Kauker (2003), i.e. a stationary bias of $-0.63 \%$ is removed
1970-1998, as input for their statistical model to calculate redundancy modes. The predictors are $97 \mathrm{yr}$ long records of SLP, air temperature, and precipitation. Spatial patterns were selected by maximizing predictand variance during the 'learning' period 1980-1998. The remainder period 1970-1979 was used for validation (Kauker \& Meier 2003).

Standard bulk formulae are utilized (Meier 2002). Wind speeds at $10 \mathrm{~m}$ height are calculated from geostrophic winds according to Bumke et al. (1998). As the SLP fields are reconstructed only as daily mean values, the energy flux to inertial motions is underestimated (D'Asaro 1985). Therefore, the reducstagnation periods the freshwater inflow is increased (Fig. 1) and an anomalous west wind component over the Baltic Sea region hampers the salt transport into the Baltic (Meier \& Kauker 2003).

\section{MODEL STRATEGY}

In this study, sensitivity experiments for 1902-1998 were performed using a 3D coupled sea-ice-ocean model for the Baltic Sea. The model used is the Rossby Centre Ocean model RCO (Meier et al. 1999, 2003, Meier 2001, Meier \& Faxén 2002). RCO utilizes the code of the Ocean Circulation Climate Advanced Modeling (OCCAM) project of the Bryan-Cox-Semtner primitive equation ocean model with a free surface (Webb et al. 1997). Open boundary conditions according to Stevens (1990) are implemented in the northern Kattegat. An improved turbulence scheme is used (Meier 2001). The ocean model in RCO is coupled with a Hibler-type (Hibler 1979), 2-level (open water and sea ice), dynamic-thermodynamic sea-ice model. The model depths are based on realistic bottom topography data (Seifert \& Kayser 1995). In the present study, RCO is used with a horizontal resolution of 6 nautical miles and with 41 vertical levels with layer thicknesses between 3 and $12 \mathrm{~m}$.

Whereas 100 yr long records of river runoff and sealevel data in the Kattegat are available, an observational data set of atmospheric surface fields applicable to force a coupled sea-ice-ocean model of the Baltic Sea is missing. Therefore, a statistical model using redundancy analysis to reconstruct daily SLP and monthly surface-air and dew-point temperatures, precipitation, and cloudcover fields on a $1^{\circ} \times 1^{\circ}$ regular horizontal grid for the Baltic Sea region was developed (Kauker \& Meier 2003). Kauker \& Meier (2003) used a gridded atmospheric data set based on synoptic stations, which is available for
The Baltic Sea model is initialized with temperature and salinity observations from November 1, 1902. In all simulations, a constant deepwater salinity of $33.2 \%$ is prescribed in case of inflow at the open boundary. The standard experiment (H1) is performed with observed river runoff (Table 1). In Expt F1 climatological monthly mean runoff and precipitation have been used. The climatology is calculated for 1902-1970. In addition, sensitivity experiments with increased or decreased freshwater inflow relative to the reference period 1902-1998 were performed (Expts E1 to E5; Table 1). In these experiments the full variability of the freshwater inflow and atmospheric forcing of the past century is applied.

\section{RESULTS}

In the experiments with increased freshwater inflow of $34 \%$ (E1) and $100 \%$ (E2), the salinity in the whole water column at the station BY15 (eastern Gotland

Table 1. Freshwater inflow (1902-1998) and steady-state Baltic Sea average salinity calculated from RCO results (1969-1998). The relative change of the total freshwater inflow refers to the inflow used in the standard experiment (H1)

\begin{tabular}{|lccrrr|}
\hline Run & $\begin{array}{c}\text { Runoff } \\
\left(\mathrm{m}^{3} \mathrm{~s}^{-1}\right)\end{array}$ & $\begin{array}{c}\text { Net precipitation } \\
\left(\mathrm{m}^{3} \mathrm{~s}^{-1}\right)\end{array}$ & $\begin{array}{c}\text { Sum } \\
\left(\mathrm{m}^{3} \mathrm{~s}^{-1}\right)\end{array}$ & $\begin{array}{c}\text { Change } \\
(\%)\end{array}$ & $\begin{array}{c}\text { Salinity } \\
(\% \circ)\end{array}$ \\
\hline H1 & 14085 & 2030 & 16115 & 0 & 7.98 \\
F1 & 14085 & 2030 & 16115 & 0 & 7.98 \\
E1 & 18927 & 2728 & 21655 & +34 & 4.56 \\
E2 & 28170 & 4060 & 32230 & +100 & 1.36 \\
E3 & 56340 & 8120 & 64460 & +300 & 0.03 \\
E4 & 11132 & 1604 & 12736 & -21 & 10.99 \\
E5 & 4370 & 630 & 5000 & -69 & 22.99 \\
& & & & & \\
\hline
\end{tabular}

tion coefficient is increased by $11 \%$. 
a

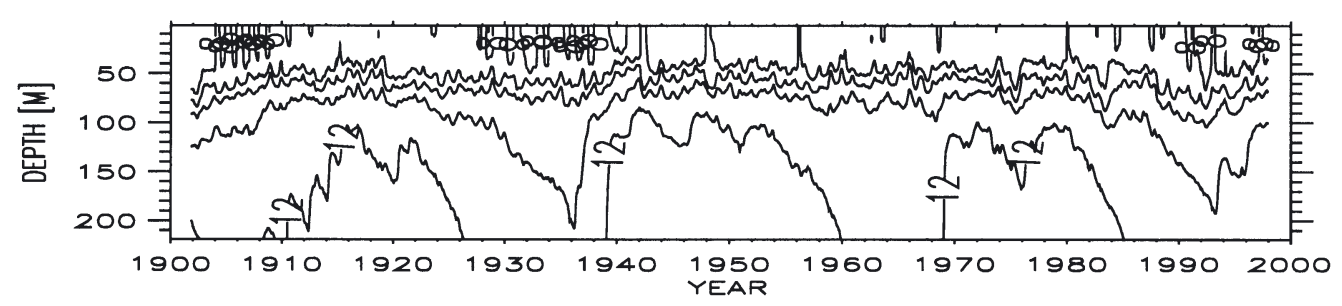

b

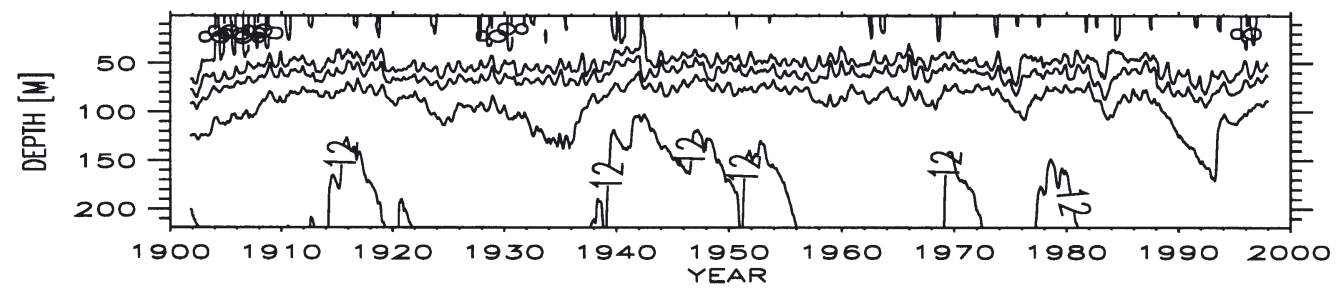

C

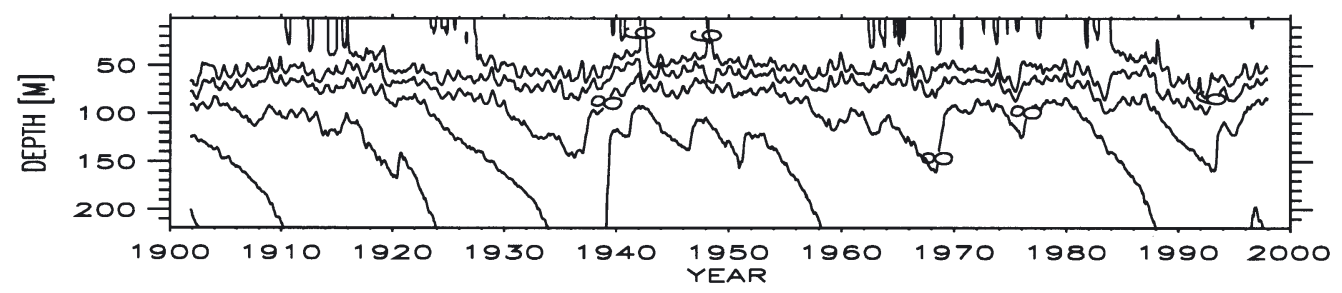

d



e

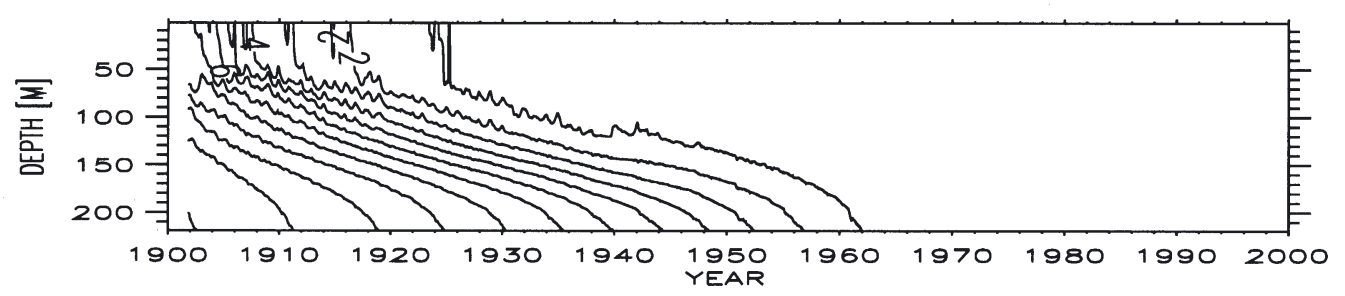

f

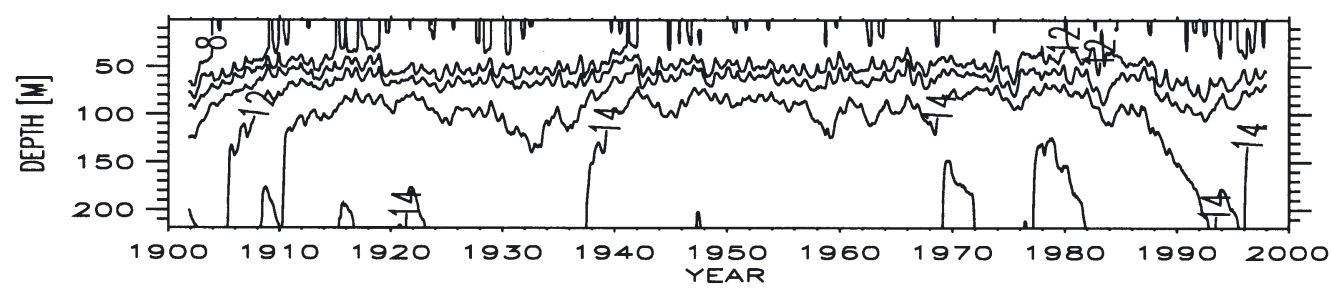

g

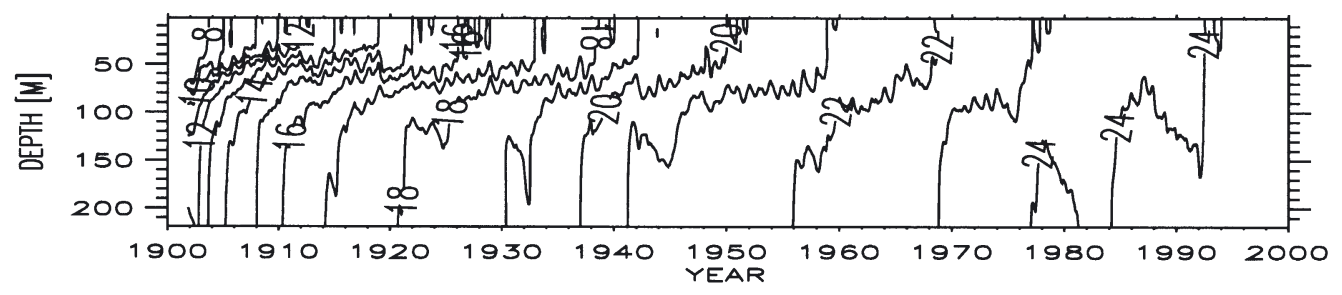

Fig. 4. Salinity (in \%o) as function of time and depth in the eastern Gotland Basin (Stn BY15). (a) Observed freshwater supply (H1); (b) climatological monthly mean river runoff and precipitation for 1902-1970 (F1). Increased or decreased freshwater inflow: (c) $+34 \%$ (E1), (d) $+100 \%$ (E2), (e) $+300 \%$ (E3), (f) $-21 \%$ (E4), and (g) $-69 \%$ (E5). The contour interval is $1 \%$ 


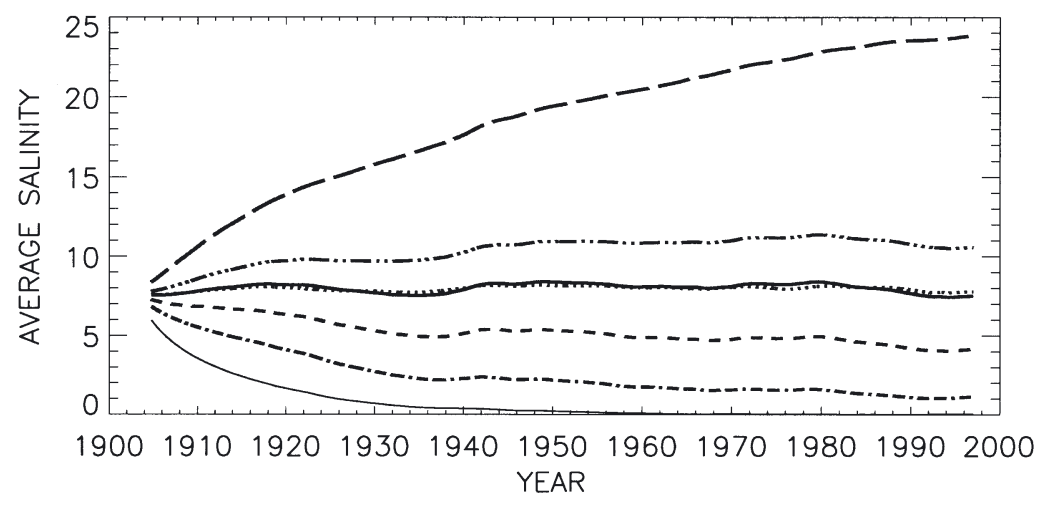

Fig. 5. Four year running mean average salinity in the Baltic Sea without the Kattegat (in \%): H1: solid line; F1: dotted line; E1: dashed line; E2: dash-dotted line; E3: thin solid line; E4: dash-triple-dotted line; and E5: long-dashed line

even before the critical salinity is reached in the Gotland Basin, indicating that winter mixing in the Arkona Basin and Bornholm Basin might influence the saltwater intrusions into the Gotland Basin and, consequently, the halocline in the Baltic Proper.

The natural decadal variability of salinity in the Gotland Basin caused by the freshwater inflow variations is much smaller than the salinity changes in the experiments with modified freshwater forcing, E1 to E5 (cf. Fig. $4 \mathrm{a}, \mathrm{b})$. This is also evident from the average salinity (Fig. 5). Although the 4 yr running mean freshwater inflow can deviate from the long-term mean

Basin) is reduced significantly (Fig. 4c,d) compared to Expt H1 (Fig. 4a). Nevertheless, the Baltic Sea will not become a freshwater sea according to our model results. Even in the case of $100 \%$ increased freshwater inflow (i.e. a total freshwater inflow of $32230 \mathrm{~m}^{3} \mathrm{~s}^{-1}$ ), a pronounced halocline at about 60 to $100 \mathrm{~m}$ of depth is found. In this experiment (E2), at the end of the integration the salinity in the Gotland Basin is about 6 to $7 \%$ lower in the surface layer and about 8 to $9 \%$ lower in the bottom layer compared to Expt H1. The final quasi steady-state is characterized by salinities of about 1 to $2 \%$ in the surface layer and by salinities of about 3 to $4 \%$ in the bottom layer (Fig. 4 d). In Expt E1 the salinity decrease is constant for the whole water column and amounts to 3 to $4 \%$ (Fig. $4 \mathrm{c}$ ). The Baltic Sea will become a freshwater sea when the freshwater inflow is increased by a factor of 4 (E3), i.e. a total freshwater inflow of $64460 \mathrm{~m}^{3} \mathrm{~s}^{-1}$ (Fig. 4e). After about $80 \mathrm{yr}$ of integration the salinity in the Gotland Basin is smaller than $0.01 \%$ in the whole water column.

Experiments with reduced freshwater inflow of $-21 \%$ (E4) and $-69 \%$ (E5) underline the important role of the freshwater inflow for the system. We found significantly increased salinities (Fig. 4f,g). In Expt E4, the salinity is about 3 to $4 \%$ higher in the surface layer and about 2 to $3 \%$ higher in the bottom layer at the end of the integration compared to Expt H1. In Expt E5, the salinity is even about 16 to $17 \%$ higher in the surface layer and about 13 to $14 \%$ higher in the bottom layer. Interestingly, in Expt E5 the stratification at Stn BY15 is very small at the end of the $96 \mathrm{yr}$ simulation (Fig. 4g). The salinity varies between 24 and $25 \%$, and the salinity difference between surface and bottom is smaller than $1 \%$. The decreasing stratification may be explained by an onset of winter mixing when the temperature of the density maximum is below freezing (Schrum \& Backhaus 1999). Winter mixing will occur if the salinity is above $24.7 \%$. The effect can be seen by $20 \%$ (Fig. 1), the impact on the average salinity is rather limited (variations are smaller than $7 \%$, see Fig. 3). The quasi-decadal freshwater inflow variations are too short compared to the response time scale of the Baltic Sea, about 35 yr.

Despite natural fluctuations the average salinity in all experiments is almost constant in time during the last $30 \mathrm{yr}$ of the simulation period, 1969-1998 (Fig. 5). The system is in a new steady state. An exception is Expt E5, with salinity still increasing after 100 yr.

\section{A STEADY-STATE BALTIC SEA MODEL}

For the discussion of the results a steady-state model is developed following Knudsen $(1899,1900)$. The approach is based upon volume and salt conservation of a 2-layer estuary (Fig. 6). It is assumed that the change in height of the high-saline water in the Arkona Basin is a linear function of the freshwater inflow perturbation and that the sum of absolute inflowing and outflowing transports does not change significantly. Finally, the halocline depth in the Baltic Proper is assumed to be constant. These assumptions

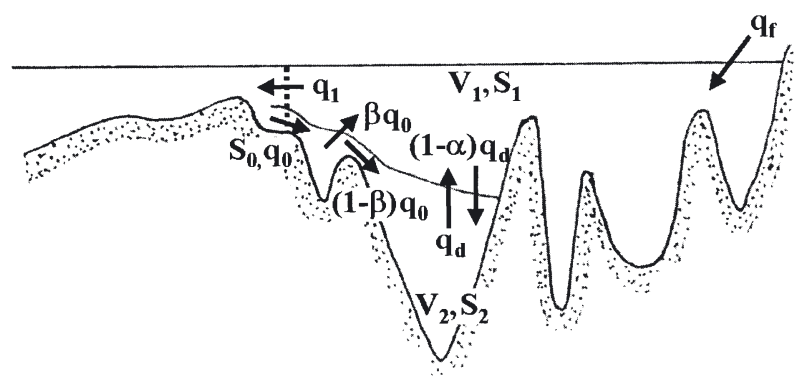

Fig. 6. Steady-state salt budget model for the Baltic Sea. The notation is explained in Appendix 1 
are supported by the 3D model results as long as the freshwater inflow changes are small (E1, E4). The steady-state model is calibrated using observations of present climate (Gustafsson 2001). For details the reader is referred to Appendix 1.

In contrast to other applications of Knudsen-like steady-state models (e.g. Welander 1974, Gustafsson 1997, Rodhe \& Winsor 2002), the entrance section in this study is located in the Arkona Basin instead of the Kattegat, because the deepwater flow in the Arkona Basin has been shown to be geostrophically controlled (Liljebladh \& Stigebrandt 1996) and the climatological mean flow is known quite well from observations (Stigebrandt 1987, Gustafsson 2001).

It is estimated that the approximations used hold as long as the freshwater variations remain smaller than $30 \%$ (Welander 1974), which is supported by the 3D model results (Fig. 4). In this range the analytical solution of the steady-state model is in good agreement with the 3D model results (Fig. 7). The phase diagram shows that the relationship between freshwater supply

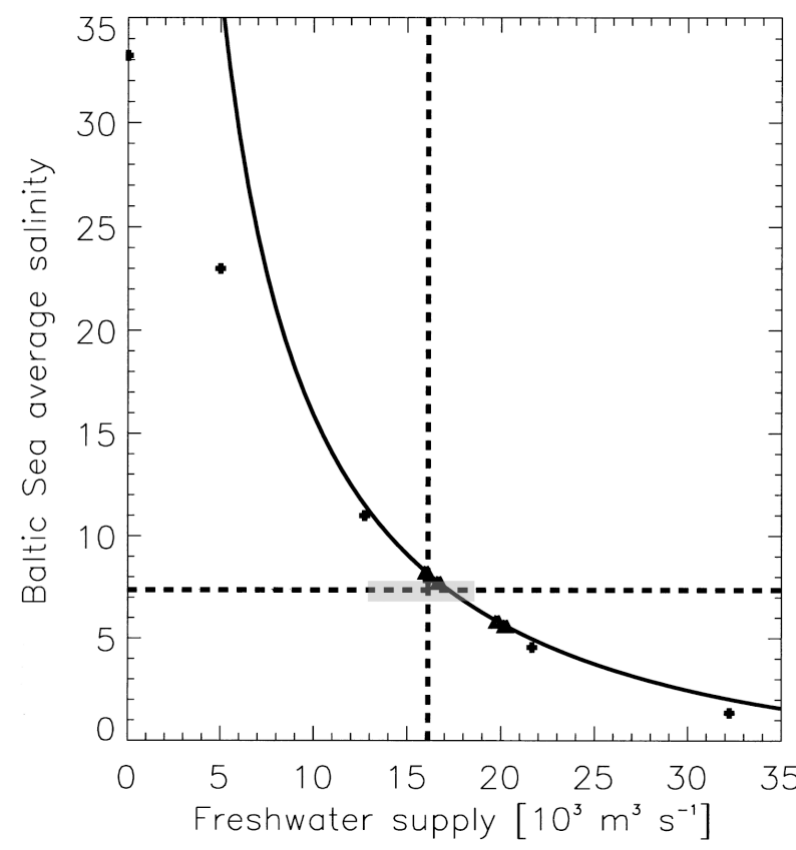

Fig. 7. Steady-state Baltic Sea average salinity as a function of the freshwater supply. The solid line shows the analytical results of the steady-state Baltic Sea model (Section 5). The plus signs denote steady-state RCO results for 1969-1998 (Table 1). For zero freshwater supply a mean salinity of $33.2 \%$ is assumed. The triangles show scenario results based upon changes of freshwater inflow in regional climate models (Section 6, Table 2). In addition, the present climate (1902-1998) with a mean salinity of $7.36 \%$ and a mean freshwater inflow of $16115 \mathrm{~m}^{3} \mathrm{~s}^{-1}$ is shown (dashed lines). Minimum and maximum values of the $4 \mathrm{yr}$ running means indicate the natural variability (shaded area)

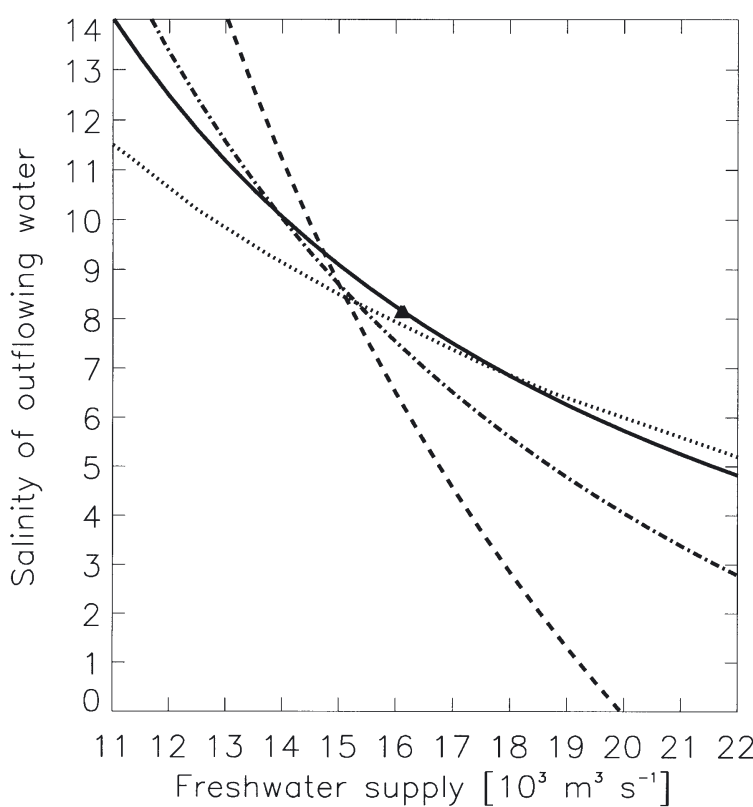

Fig. 8. Modeled steady-state salinity of the outflowing Baltic Sea surface water as a function of the freshwater supply. The solid line shows the analytical results of the present study. The dash-dotted and dashed lines show results of the semiempirical model by Rodhe \& Winsor (2002) using proportionality factors of -0.3 and -0.8 , respectively (J. Rodhe pers. comm.). The dotted line shows the results of the process oriented model by Stigebrandt (1983). The triangle denotes the observed present climate

and average salinity of the final steady-state is nonlinear (Fig. 7). Increased freshwater inflow causes decreased average salinity. However, the decrease is relatively smaller in the case of larger freshwater supply. The agreement between the analytical steady-state model and RCO suggests that the basic principles of the steady-state estuarian circulation of the Baltic Sea do not differ significantly between the 2 approaches.

As the Kattegat surface water is tightly coupled to the state of the Baltic Sea, the salinity of the outflowing water has been analyzed in several long-term studies of the Baltic Sea (e.g. Stigebrandt 1983, Gustafsson 1997, Rodhe \& Winsor 2002). The salinity of the outflowing water in our steady-state model is somewhat more sensitive to the freshwater supply than the results of the process-oriented model presented by Stigebrandt (1983) (Fig. 8). As both model approaches are based upon the same processes, a larger discrepancy is not expected. However, the semi-empirical model presented by Rodhe \& Winsor (2002) is about a factor of 2 to 5 more sensitive (J. Rodhe pers. comm.). With a $33 \%$ increased freshwater inflow compared to present climate, the salinity of the outflowing water in their model is zero if a proportionality factor of -0.8 (upper limit) is used (J. Rodhe pers. comm.). Rodhe \& 
Winsor (2002) assumed that the variations of the salinity difference between the surface layer and the deepwater is a linear function of the freshwater inflow variations. The proportionality factor has been estimated from annual mean data of accumulated freshwater inflow and freshwater content perturbations during 1921-1996. However, such a linear relationship may not exist. Only about half of the decadal variability of the average salinity of the Baltic Sea is explained by the freshwater inflow variability (Meier \& Kauker 2003). The remainder is very likely associated with variations of the zonal wind component (Meier \& Kauker 2003). As the variability of the surface layer salinity is much smaller than the variability of the deepwater salinity, the difference between the two is significantly correlated to the average salinity. Consequently, the relationship between the perturbations of the salinity difference and the freshwater inflow is non-linear. This might explain why the calibration method used by Rodhe \& Winsor (2002) yields a much stronger sensitivity.

\section{SCENARIOS}

Although there is no significant trend in the annual mean freshwater inflow (Fig. 1), a changing climate has been detected on the regional scale. Alexandersson (2002) analyzed air temperature and precipitation at Swedish stations for 1860-2001. He found a significant increase in the annual mean temperature for the whole of Sweden. Also, the annual mean precipitation increased mainly in the northern parts of Sweden. However, the analysis of selected long time series of unreg- ulated rivers in Sweden showed no significant trends during the last century (Lindström 2002). The difference between precipitation and runoff is explained by evapotranspiration. Due to 3 main reasons it is assumed that evapotranspiration has also increased during the last century. Firstly, temperature has increased and consequently also the direct evaporation and the transpiration of the vegetation. Secondly, the vegetation period has become longer due to milder spring and autumn seasons. Thirdly, the biomass of the forests has increased. Today more areas are covered by forests and the density of the trees is higher due to a changed composition compared to the eighteenth century or earlier (Alexandersson 2002). Therefore, the estimated increase in runoff as simulated with regional climate models is not unlikely, because these scenarios are projections towards the late twenty-first century. Räisänen et al. (2003) studied the changing climate in Europe in regional simulations for 2071-2100. In this section, their results for future precipitation, evaporation and runoff will be utilized to produce scenarios of the average salinity of the Baltic Sea.

Scenario results differ depending on the applied climate model and depending on the utilized greenhouse-gas and aerosol-emission scenario (Räisänen et al. 2003). Regional time-slice simulations recently performed at the Rossby Centre are summarized in Table 2. In these 30 yr long simulations a high-resolution atmosphere-sea-ice-ocean-land-surface model, RCAO, with lateral boundary data from 2 global general circulation models (GCMs), HadAM3H (RCAO-H) and ECHAM4/OPYC3 (RCAO-E), was used. RCAO consists of the atmospheric model RCA (Bringfelt et al. 2001, Jones 2001) and the ocean model RCO. Both

Table 2. Freshwater inflow (runoff and net precipitation, $P-E$ ) in six $30 \mathrm{yr}$ long regional climate simulations using RCAO and associated steady-state salinity calculated with the analytical steady-state model (Section 5). In the regional climate simulations lateral boundary data from 2 GCMs, HadAM3H (RCAO-H) and ECHAM4/OPYC3 (RCAO-E), were used. The river discharges were calculated from precipitation and air temperature off-line (P. Graham pers. comm.). The changes of the total freshwater inflow in the scenarios (A2, B2) are calculated relative to the corresponding control runs (CTL). The 'direct' steady-state salinity is estimated using the uncorrected total freshwater inflow ('direct') from the scenario simulations. In the $\Delta$-change approach, the steady-state salinity is calculated from the sum of today's freshwater inflow $\left(16115 \mathrm{~m}^{3} \mathrm{~s}^{-1}\right)$ and the calculated freshwater inflow change (scenario minus control run). Thereby the salinity is linearly corrected (with $-0.81 \%$ ) in such a way that for the present climate a value of $7.36 \%$ is obtained

\begin{tabular}{|lccccccc|}
\hline Run & $\begin{array}{c}\text { Runoff } \\
\left(\mathrm{m}^{3} \mathrm{~s}^{-1}\right)\end{array}$ & $\begin{array}{c}P \text {-E } \\
\left(\mathrm{m}^{3} \mathrm{~s}^{-1}\right)\end{array}$ & $\begin{array}{c}\text { Total inflow } \\
(\text { direct }) \\
\left(\mathrm{m}^{3} \mathrm{~s}^{-1}\right)\end{array}$ & $\begin{array}{c}\text { Total inflow } \\
(\Delta \text {-change }) \\
\left(\mathrm{m}^{3} \mathrm{~s}^{-1}\right)\end{array}$ & $\begin{array}{c}\text { Change } \\
(\%)\end{array}$ & $\begin{array}{c}\text { Salinity } \\
(\text { direct }) \\
(\%)\end{array}$ & $\begin{array}{c}\text { Salinity } \\
(\Delta \text {-change }) \\
(\%)\end{array}$ \\
\hline RCAO-H CTL & 17703 & 1021 & 18724 & 16115 & 0 & 6.42 & 7.36 \\
RCAO-H A2 & 17903 & 726 & 18629 & 16020 & -1 & 3.48 & 6.10 \\
RCAO-H B2 & 18370 & 924 & 19294 & 16685 & 0 & 3.54 & 7.36 \\
RCAO-E CTL & 22789 & 2909 & 25698 & 16115 & 14 & 2.59 & 5.04 \\
RCAO-E A2 & 26174 & 3199 & 29373 & 19790 & 16 & 2.50 & 4.82 \\
RCAO-E B2 & 26327 & 3482 & 29809 & 20226 & & \\
\hline
\end{tabular}


component models are fully coupled (Döscher et al. 2002). The 2 control simulations (CTL) represent the recent (1961-1990) climate and the 4 scenario simulations (A2, B2) represent the climate of the late twentyfirst century (2071-2100). The A2 scenario assumes relatively large (in comparison with the other IPCC SRES scenarios) and continuously increasing emissions of the major anthropogenic greenhouse gases, $\mathrm{CO}_{2}, \mathrm{CH}_{4}$ and $\mathrm{N}_{2} \mathrm{O}$ (Nakićenović et al. 2000). The B2 scenario also features increases in $\mathrm{CO}_{2}$ and $\mathrm{CH}_{4}$ emissions, but here they are smaller, in the lower midrange of the SRES scenarios. However, this difference is partly compensated for by larger sulphur emissions in A2 than in B2. The emission scenarios may be characterized best in terms of the global mean air-temperature increase. In the B2 scenario the air-temperature rise amounts to $2.3^{\circ} \mathrm{C}$ in $\mathrm{HadAM} 3 \mathrm{H}$ and $2.6^{\circ} \mathrm{C}$ in ECHAM4/OPYC3. The corresponding values for the A2 scenario are 3.2 and $3.4^{\circ} \mathrm{C}$, respectively.

There are 2 reasons why the time-slice approach using a regional coupled atmosphere-sea-ice-ocean climate model fails for salinity scenarios. Firstly, the $30 \mathrm{yr}$ long time-slice experiments are too short. The Baltic Sea cannot adjust to the altered freshwater inflow completely because of the long response time scale of about $35 \mathrm{yr}$. A new steady state for salinity requires a longer integration (Fig. 5). Hence, the climate of the time slices depends on the initial conditions, which are unknown for the scenarios. In the experiments discussed here the same initial conditions for temperature and salinity as used in the control simulations were applied to the time-slice experiments of the future period 2071-2100. As the freshwater inflow in the RCAO-E scenarios is changing significantly, there is a spin-up problem, as discussed by Meier (2002). Secondly, in both control simulations (RCAO-H CTL and RCAO-E CTL) precipitation and runoff are unrealistically high. No flux corrections were applied. We found, for example, that the total freshwater inflow is $59 \%$ larger in RCAO-E CTL compared to the observed climatological long-term mean value for 1902-1998 (Table 2).

To overcome these obstacles the analytical model of Section 5 is used to estimate the steady-state average salinity of the Baltic Sea in changing climate. We applied the so-called $\Delta$-change approach. Only the freshwater inflow differences between the control and scenario integrations are used. As the freshwater inflows in the scenarios driven by HadAM3H differ only by -1 (RCAO-H A2) or $3 \%$ (RCAO-H B2) from the freshwater inflow in the control run, the calculated average salinities in the scenarios are, with 7.43 and $6.93 \%$, respectively, close to the value of present climate of $7.36 \%$ (Table 2). Due to the larger freshwater inflow changes in the scenarios driven by ECHAM4/
OPYC3 of 14 (RCAO-E A2) and $16 \%$ (RCAO-E B2), the scenario salinities are only 5.04 and $4.82 \%$, respectively (Table 2). These changes are larger than the natural variability of about $1 \%$. In Fig. 7, the steady-state salinities of the scenarios are depicted (triangles) for comparison with the natural variability (shaded area). The results demonstrate that relatively small changes of the freshwater inflow are sufficient to separate anthropogenic climate changes of salinity from the natural variability of the past century. Although the calculated changes of the freshwater inflow are smaller than the maximum decadal variation of the freshwater inflow during the past century (about $20 \%$, see Fig. 1), the associated salinity changes are detectable because the freshwater inflow anomalies are persistent, i.e., the anomalies last much longer than the response time scale of the Baltic Sea. If the freshwater inflows from the scenarios driven by ECHAM4/OPYC3 are directly applied to calculate the average salinity, we find very small values of 2.59 and $2.50 \%$, showing the problem of the largely biased precipitation in RCAO-E (Table 2).

\section{DISCUSSION}

The presented experiments using a 3D model are performed under several assumptions. Firstly, the Kattegat deepwater salinity at the northern boundary of the model is assumed to be constant. In RCO a value of $33.2 \%$ is utilized. This is the observed median salinity at $36 \mathrm{~m}$ depth at the open sea station P2, located north of the model border in the northern Kattegat $\left(57^{\circ} 52^{\prime} \mathrm{N}, 11^{\circ} 18^{\prime} \mathrm{E}\right)$. At this station the difference between the 25 and $75 \%$ quantiles amounts to about $1 \%$ at $40 \mathrm{~m}$ and to about $0.5 \%$ at $100 \mathrm{~m}$. As the observations show only a small amount of variability, the assumption of constant deepwater salinity at the open boundary is justified as long as the changes in the freshwater inflow are not too large. In contrast, the variability of the sea-surface salinity in the northern Kattegat is large. At P2 the difference between the 25 and $75 \%$ quantiles amounts to about $7 \%$. The sensitivity of the average salinity in RCO to the open boundary conditions is illustrated by the results of 2 additionally performed experiments for 1902-1998. In the first experiment (S1), the surface layer salinity at the open boundary is reduced by $5 \%$ compared to Expt H1. In the second experiment (S2), the surfacelayer and deepwater salinities at the open boundary are reduced by 5 and $6 \%$, respectively. The average (uncorrected) salinity of the Baltic Sea without the Kattegat of the last $30 \mathrm{yr}$ of the integration amounts to $7.69 \%$ in Expt $\mathrm{S} 1$ and to $5.00 \%$ in Expt S2. The corresponding salinity in Expt H1 is $7.98 \%$ (Table 1). Thus, 
the deepwater salinity in the Kattegat plays an important role in the determination of the average salinity. However, the impact of the surface layer salinity at the model boundary is only small.

Secondly, we assume that the sensitivity of a coarse resolution model is representative for the Baltic Sea. However, the response might be different if mesoscale eddies are considered. Other model shortcomings might also contribute to a biased sensitivity. For example, the simulations very likely overestimate the frequency and strength of the saltwater inflows into the Arkona Basin, as mentioned in Section 2 (see also Meier \& Kauker 2003). However, the simulated deepwater volume and salt fluxes from the Arkona Basin into the Bornholm Basin are in close agreement with fluxes derived by Gustafsson (2001) from observations (Meier \& Kauker 2003). At Stolpe Channel the uncertainty of the climatological mean deepwater flow calculated from observations is quite large. The model transports are at the upper limit of available observations (Meier \& Kauker 2003). Further investigations are still necessary to understand the vertical circulation of the Baltic Sea deepwater and to evaluate the 3D Baltic Sea model.

Thirdly, it is assumed that the representation of the physics in the model continues to work in the cases of anomalously reduced or increased freshwater inflow. For example, the mixing parametrizations have not been changed during the series of experiments. We do not know whether these parametrizations are applicable in a completely different parameter space. For example, the used parametrization for breaking of internal waves is calibrated for present climate conditions (Meier 2001). Hence, the results of the sensitivity experiments with freshwater inflow changes larger than $30 \%$ should be considered with care. This is especially true for the finding that the Baltic Sea will become a freshwater sea when the freshwater inflow is increased by a factor of 4 . For freshwater inflow changes smaller than $30 \%$ the parametrizations are very likely applicable and our results suggest that the Baltic Sea will not become a freshwater sea. Thereby it is assumed that the saltwater inflow variability of the past century does not change.

In the scenarios for the average salinity of the Baltic Sea using the analytical steady-state model, we have utilized the $\Delta$-change approach to attenuate the systematic errors of the regional climate models. However, significant effects of systematic errors can be ruled out only if the systematic errors are small compared to the changes computed (Machenhauer et al. 1998). Therefore, we must be careful with final conclusions. A detailed discussion of the RCAO boundary data is needed, including their systematic errors and the effect of these errors on the freshwater input to the Baltic Sea. Such a discussion is far beyond the scope of the present paper.

\section{CONCLUSIONS}

(1) Changes of the freshwater supply on longer than decadal time scales have an important impact on the stratification in the Baltic Sea.

(2) The relationship between freshwater supply and average salinity of the final steady state is non-linear. The sensitivity of the salinity in the 3D Baltic Sea model is slightly higher than in the process-oriented model presented by Stigebrandt (1983) but much smaller than in the semi-empirical model presented by Rodhe \& Winsor (2002).

(3) The halocline depth in about 60 to $100 \mathrm{~m}$ in the Baltic Proper does not change with $30 \%$ increased or reduced freshwater inflow.

(4) The results of the simple analytical steady-state salt budget model of this study are in agreement with the results of the 3D model if the freshwater inflow changes are smaller than $30 \%$.

(5) The analytical salt budget model is a useful and simple tool to estimate future Baltic Sea salinity. The largest increase in the freshwater inflow of $16 \%$ is found in a B2 scenario utilizing RCAO with lateral boundary data from ECHAM4/OPYC3. The corresponding estimated average salinity is about $35 \%$ lower than the present value and amounts to $4.82 \%$. Such a large change is outside the range of natural variability of the past century. However, even in this scenario the Baltic Sea will not become a freshwater sea.

Acknowledgements. This study was performed within the Swedish Regional Climate Modeling program (SWECLIM). SWECLIM was founded by the Foundation for Strategic Environmental Research (MISTRA) and by the Swedish Meteorological and Hydrological Institute (SMHI). The simulations were performed on the Silicon Graphics Origin 3800 at the Swedish National Supercomputer Centre in Linköping, Sweden. Special thanks are given to Silke Malz for the preparation of Fig. 6. We would like to thank the 3 anonymous reviewers for their constructive comments.

\section{LITERATURE CITED}

Alexandersson H (2002) Temperatur och nederbörd i Sverige 1860-2001. Reports Meteorologi No. 104, Swedish Meteorological and Hydrological Institute, Norrköping

Bergström S, Carlsson B (1994) River runoff to the Baltic Sea: 1950-1990. Ambio 23:280-287

Bringfelt B, Räisänen J, Gollvik S, Lindström G, Graham LP, Ullerstig A (2001) The land surface treatment for the 
Rossby Centre Regional Atmospheric Climate Modelversion 2 (RCA2). Reports Meteorology and Climatology No. 98, Swedish Meteorological and Hydrological Institute, Norrköping

Bumke K, Karger U, Hasse L, Niekamp K (1998) Evaporation over the Baltic Sea as an example of a semi-enclosed sea. Contrib Atmos Phys 71:249-261

Cyberski J, Wroblewski A (2000) Riverine water inflows and the Baltic Sea water volume 1901-1990. Hydrol Earth Syst Sci 4:1-11

D'Asaro EA (1985) The energy flux from the wind to nearinertial motions in the surface mixed layer. J Phys Oceanogr 15:1043-1059

Döscher R, Willén U, Jones C, Rutgersson A, Meier HEM, Hansson U, Graham LP (2002) The development of the regional coupled ocean-atmosphere model RCAO. Boreal Environ Res 7:183-192

Fischer H, Matthäus W (1996) The importance of the Drogden Sill in the Sound for major Baltic inflows. J Mar Syst 9: 137-157

Gustafsson B (1997) Interaction between Baltic Sea and North Sea. Dtsch Hydrogr Z 49:165-183

Gustafsson BG (2001) Quantification of water, salt, oxygen and nutrient exchange of the Baltic Sea from observations in the Arkona Basin. Cont Shelf Res 21:1485-1500

Hibler WD (1979) A dynamic thermodynamic sea ice model. J Phys Oceanogr 9:817-846

Janssen F, Schrum C, Backhaus J (1999) A climatological dataset of temperature and salinity for the North Sea and the Baltic Sea. Dtsch Hydrogr Z Suppl 9

Jones C (2001) A brief description of RCA2 (Rossby Centre Atmosphere Model Version 2). SWECLIM Newsletter No. 11, Swedish Meteorological and Hydrological Institute, Norrköping

Kauker F, Meier HEM (2003) Modeling decadal variability of the Baltic Sea. Part 1: Reconstructing atmospheric surface data for the period 1902-1998. J Geophys Res 108(C8): 3267

Knudsen M (1899) The hydrographic conditions in the Danish waters inside Skagen in 1894-98 (in Danish). Komm For Vidensk Unders I de danske farvande 2:2

Knudsen M (1900) A hydrographical theorem (in German). Ann Hydrol 28:316-320

Lass HU, Matthäus W (1996) On temporal wind variations forcing salt water inflows into the Baltic Sea. Tellus 48A: 663-671

Liljebladh B, Stigebrandt A (1996) Observations of the deepwater flow into the Baltic Sea. J Geophys Res 101: 8895-8911

Lindström G (2002) Vattentillgång och höga flöden i Sverige under 1900-talet. Reports Hydrology No. 18, Swedish Meteorological and Hydrological Institute, Norrköping

Machenhauer B, Windelband $M$, Botzet $M$, Hesselbjerg Christensen J, Deque M, Jones R G, Ruti PM, Visconti G (1998) Validation and analysis of regional present-day climate and climate change simulations over Europe. Report No. 275, Max Planck Institute for Meteorology, Hamburg

Matthäus W, Franck H (1992) Characteristics of major Baltic inflows - a statistical analysis. Cont Shelf Res 12: $1375-1400$

Meier HEM (2001) On the parameterization of mixing in 3D Baltic Sea models. J Geophys Res 106:30997-31016

Meier HEM (2002) Regional ocean climate simulations with a 3D ice-ocean model for the Baltic Sea. Part 1: Model experiments and results for temperature and salinity. Clim Dyn 19:237-253
Meier HEM, Faxén T (2002) Performance analysis of a multiprocessor coupled ice-ocean model for the Baltic Sea. J Atmos Ocean Technol 19:114-124

Meier HEM, Kauker F (2003) Modeling decadal variability of the Baltic Sea. Part 2: The role of freshwater inflow and large-scale atmospheric circulation for salinity. J Geophys Res (in press)

Meier HEM, Döscher R, Coward AC, Nycander J, Döös K (1999) RCO-Rossby Centre regional Ocean climate model: model description (version 1.0) and first results from the hindcast period 1992/93. Reports Oceanography No. 26, Swedish Meteorological and Hydrological Institute, Norrköping

Meier HEM, Döscher R, Faxén T (2003) A multiprocessor coupled ice-ocean model for the Baltic Sea: application to salt inflow. J Geophys Res 108(C8):3273

Mikulski Z (1986) Inflow from drainage basin. In: Water balance of the Baltic Sea-Baltic Sea Environment Proceedings, Vol 16. Baltic Marine Environment Protection Commission, Helsinki, p 24-34

Nakićenović N and 27 others (2000) Emission scenarios. A Special Report of Working Group III of the Intergovernmental Panel on Climate Change, Cambridge University Press, Cambridge

Omstedt A, Gustafsson B, Rodhe J, Walin G (2000) Use of Baltic Sea modelling to investigate the water cycle and the heat balance in GCM and regional climate models. Clim Res 15:95-108

Räisänen J, Hansson U, Ullerstig A, Döscher R, Graham LP, Jones C, Meier HEM, Samuelsson P, Willén U (2003) European climate in the late 21st century: regional simulations with two driving global models and two forcing scenarios. Clim Dyn (in press)

Rodhe J, Winsor P (2002) On the influence of the freshwater supply on the Baltic Sea mean salinity. Tellus 54A: 175-186

Rutgersson A, Omstedt A, Räisänen J (2002) Net precipitation over the Baltic Sea during present and future climate conditions. Clim Res 22:27-39

Schinke H, Matthäus W (1998) On the causes of major Baltic inflows - an analysis of long time series. Cont Shelf Res 18:67-97

Schrum C, Backhaus JO (1999) Sensitivity of atmosphere-ocean heat exchange and heat content in the North Sea and the Baltic Sea. Tellus 51A:526-549

Seifert T, Kayser B (1995) A high resolution spherical grid topography of the Baltic Sea. Meereswiss Ber Warnemünde 9:73-88

Stevens DP (1990) On open boundary conditions for three dimensional primitive equation ocean circulation models. Geophys Astrophys Fluid Dyn 51:103-133

Stigebrandt A (1983) A model for the exchange of water and salt between the Baltic and the Skagerrak. J Phys Oceanogr 13:411-427

Stigebrandt A (1987) Computations of the flow of dense water into the Baltic Sea from hydrographical measurements in the Arkona Basin. Tellus 39A:170-177

Webb DJ, Coward AC, de Cuevas BA, Gwilliam CS (1997) A multiprocessor ocean circulation model using message passing. J Atmos Ocean Technol 14:175-183

Welander P (1974) Two-layer exchange in an estuary basin, with special reference to the Baltic Sea. J Phys Oceanogr $4: 542-556$

Winsor P, Rodhe J, Omstedt A (2001) Baltic Sea ocean climate: an analysis of $100 \mathrm{yr}$ of hydrographic data with focus on the freshwater budget. Clim Res 18:5-15 
Appendix 1. Analytical model description

The steady-state water exchange in an estuary can be described as a 2-layer flow with an outflow in the upper layer $\left(q_{1}\right)$ and inflow in the lower layer $\left(q_{0}\right)$ (see Fig. 6). According to Knudsen $(1899,1900)$ the conservation of volume and salinity yields

$$
\text { and } \begin{gathered}
q_{1}-q_{0}=q_{\mathrm{f}} \\
S_{1} q_{1}-S_{0} q_{0}=0
\end{gathered}
$$

where $q_{\mathrm{f}}\left(16115 \mathrm{~m}^{3} \mathrm{~s}^{-1}\right)$ is the freshwater inflow and $S_{0}$ and $S_{1}$ are the salinities of the inflowing and outflowing water, respectively. Gustafsson (2001) calculated from observations in the twentieth century at Stn BY2 in the Arkona Basin the climatological mean values $q_{0}=22400 \mathrm{~m}^{3} \mathrm{~s}^{-1}$ and $S_{1}=8.16 \%$. Further, it is known that the deepwater flow in the Arkona Basin is geostrophically controlled (Liljebladh \& Stigebrandt 1996), i.e.

$$
q_{0}=\frac{g \gamma}{2 f}\left(S_{0}-S_{1}\right)(H-h)^{2}
$$

where $g$ is the gravitational acceleration, $\gamma=8 \times 10^{-4}, f$ is the Coriolis parameter, $H$ is the water depth, and $h$ is the depth of the halocline. According to Welander (1974), the steady-state salinity in the lower layer of the interior of the estuary $\left(S_{2}\right)$ can be calculated from

$$
S_{2}-S_{2}=\alpha\left(S_{0}-S_{1}\right)
$$

where $\alpha$ is the erosion coefficient. If diffusive transport across the halocline is denoted $q_{\mathrm{d}}$, the entrainment of upper-layer water into the lower layer is defined as $(1-$ $\alpha) q_{\mathrm{d}}$. If $\alpha=0$, entrainment and diffusion are equal. If $\alpha=1$, no upper-layer water penetrates into the lower layer. A steady state exists for this model type only if entrainment is smaller than diffusion, i.e. $0 \leq \alpha \leq 1$. The value of $\alpha$ is unknown. Fortunately, it turned out that the analytical solution is not very sensitive to $\alpha$ in the parameter range of present climate (we have chosen $\alpha=0.01$ ).

Another important process is entrance mixing in the Arkona Basin. The inflowing water of salinity $S_{0}$ is assumed to be partly mixed into the upper layer, while the rest sinks into the lower layer. The respective fractions are $\beta$ and $1-\beta$ (Fig. 6). However, in our approach, entrance mixing is not needed for the calculation of the average salinity in the steady state. The average salinity of the Baltic Sea is defined as

$$
\bar{S}=(1-\lambda) S_{1}+\lambda S_{2}
$$

where the relative volume of the lower layer $\lambda=0.1$. Using Eqs (1)-(4) it follows from Eq. (5) that

$$
\bar{S}=\frac{2 f}{g \gamma} \frac{q_{0}}{(H-h)^{2}} \frac{q_{0}+\alpha \lambda q_{\mathrm{f}}}{q_{\mathrm{f}}}
$$

Eq. (6) is solved for present climate using the results by Gustafsson (2001). For small changes $\Delta q_{\mathrm{f}}$, the following assumptions are made: $\Delta q_{0}=-0.5 \Delta q_{\mathrm{f}}, \Delta h=\Delta q_{\mathrm{f}} / q_{\mathrm{f}}$, and $\Delta \lambda=0$. With these assumptions, the average salinity can be calculated from Eq. (6) as a function of the freshwater inflow. Thereby, $H-h$ is calculated from $\Delta h=\Delta q_{\mathrm{f}} / q_{\mathrm{f}}$ and the value for present climate $(H-h=11.1 \mathrm{~m})$.
Editorial responsibility: Hans von Storch, Geesthacht, Germany
Submitted: January 20, 2003; Accepted: July 7, 2003 Proofs received from author(s): September 15, 2003 